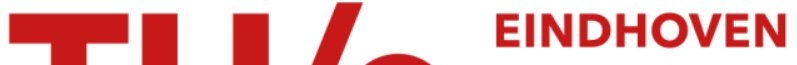 UNIVERSITY OF TECHNOLOGY
}

\section{Synthesis, purification and characterization of cationic latices produced by the emulsion copolymerization of styrene with 3- (methacrylamidinopropyl)trimethylammonium chloride}

Citation for published version (APA):

Streun, van, K. H., Belt, W. J., Piet, P., \& German, A. L. (1991). Synthesis, purification and characterization of cationic latices produced by the emulsion copolymerization of styrene with 3-

(methacrylamidinopropyl)trimethylammonium chloride. European Polymer Journal, 27(9), 931-938.

https://doi.org/10.1016/0014-3057\%2891\%2990036-N, https://doi.org/10.1016/0014-3057(91)90036-N

DOI:

10.1016/0014-3057\%2891\%2990036-N

10.1016/0014-3057(91)90036-N

Document status and date:

Published: 01/01/1991

Document Version:

Publisher's PDF, also known as Version of Record (includes final page, issue and volume numbers)

\section{Please check the document version of this publication:}

- A submitted manuscript is the version of the article upon submission and before peer-review. There can be important differences between the submitted version and the official published version of record. People interested in the research are advised to contact the author for the final version of the publication, or visit the $\mathrm{DOI}$ to the publisher's website.

- The final author version and the galley proof are versions of the publication after peer review.

- The final published version features the final layout of the paper including the volume, issue and page numbers.

Link to publication

\footnotetext{
General rights

- You may freely distribute the URL identifying the publication in the public portal. follow below link for the End User Agreement:

www.tue.nl/taverne

Take down policy

If you believe that this document breaches copyright please contact us at:

openaccess@tue.nl

providing details and we will investigate your claim.
}

Copyright and moral rights for the publications made accessible in the public portal are retained by the authors and/or other copyright owners and it is a condition of accessing publications that users recognise and abide by the legal requirements associated with these rights.

- Users may download and print one copy of any publication from the public portal for the purpose of private study or research.

- You may not further distribute the material or use it for any profit-making activity or commercial gain

If the publication is distributed under the terms of Article 25fa of the Dutch Copyright Act, indicated by the "Taverne" license above, please 


\title{
SYNTHESIS, PURIFICATION AND CHARACTERIZATION OF CATIONIC LATICES PRODUCED BY THE EMULSION COPOLYMERIZATION OF STYRENE WITH 3-(METHACRYLAMIDINOPROPYL)TRIMETHYLAMMONIUM CHLORIDE
}

\author{
K. H. van Streun, W. J. Belt, Pieter Piet* and Anton L. German \\ Laboratory of Polymer Chemistry, Eindhoven, University of Technology, P.O. Box 513, \\ $5600 \mathrm{MB}$ Eindhoven, The Netherlands
}

(Received 10 December 1990)

\begin{abstract}
A study was made of the effect of varying the amount of 3-(methacrylamidinopropyl)trimethylammonium chloride (MAD) on the emulsion copolymerization of styrene and MAD with azo-bis(isobutyramidine hydrochloride) as initiator. The addition of MAD accelerated the polymerization and decreased the particle size. Cleaning of these latices in order to remove polyelectrolyte not incorporated in the latex particles was found to be tedious. Serum replacement, diafiltration and centrifugation appeared to be unsatisfactory since desorption of polyelectrolyte was still observed after standing or stirring. A combination of centrifugation and treatment with silica appeared to clean the latices to a satisfactory level (expressed as $\left[\mathrm{N}^{+}\right]<5 \times 10^{-7} \mathrm{~mol} / \mathrm{dm}^{3}$ ). Surface charge density, as determined by conductometric acid-base titrations, rose slightly on increasing the initial MAD concentration. Shotgrowth (two-step) emulsion polymerization or the use of a cross-linking agent (divinylbenzene) hardly affected the surface charge density.
\end{abstract}

\section{INTRODUCTION}

The immobilization of catalytic systems on insoluble supports has received considerable academic and industrial attention over the last few decades. Most of these investigations focused on organic supports that can be functionalized by chemical reactions $[1,2]$. Generally, after immobilization the activities of intrinsically highly catalytic systems have been disappointing. In most cases this is due to mass transfer limitations to the support particles (interparticle diffusion) or within the particles (intraparticle diffusion). To overcome these problems, smaller nonporous particles are needed but a drawback of particle size is the need for more sophisticated techniques to purify the resulting products.

Emulsion polymerization offers the possibility of synthesizing these small, organic, nonporous particles in the submicron region. This polymerization technique also allows the synthesis of particles with narrow particle size distribution (monodispersity). Funtionalization of these latices can then be achieved by emulsion polymerization in the presence of a functional monomer, a functional surfactant, a functional initiator or by post-polymerization modification [3].

In a conventional emulsion polymerization, latices are stabilized by surfactants. The removal of stabilizer after polymerization is difficult, and coagulation may result $[4,5]$. In the case of surfactant-free emulsion polymerization of styrene, particles are stabilized by ionic initiator residues. Potassium persulphate as initiator has been studied extensively and was found

*To whom all correspondence should be addressed. to give sulphate stabilized latices $[4,9]$. In order to obtain a better control of both particle size and surface charge density, ionic comonomers can be used. Most studies have been concerned with the stabilization by anionic groups [10-14] introduced by sulphonate-containing monomers. Other types of ionic monomers frequently used are monomers containing carboxyl groups [15-20], and nonionic hydrophilic monomers like acrylamide and acrylamide derivatives [21-24]. Surprisingly, the use of cationic comonomers is less common [25-29]. The use of surfactant-like monomers has also been reported [30-32].

Our goal is to prepare stable cationic latices with high surface charge density as supports for cobalt(II)phthalocyanine-tetrasodiumsulphonate (CoTSPc). In this paper we describe the synthesis, purification and characterization of cationic latices prepared by emulsion polymerization of styrene in the presence of the functional cationic comonomer, 3-(methacrylamidinopropyl)trimethylammonium chloride (1, MAD) and azo-bis(isobutyramidine hydrochloride) (2, AIBA) as initiator (Scheme 1).

\section{EXPERIMENTAL PROCEDURES}

\section{Emulsion polymerization}

Styrene (Merck) and divinylbenzene (DVB; $65 \mathrm{wt} \%$ divinylbenzene isomers, $30 \mathrm{wt} \%$ ethylvinylbenzene isomers; Merck) were distilled before use. AIBA (Polyscience) was used as purchased. MAD (Merck) was received as a $50 \%$ aqueous solution. The inhibitor was removed by extraction with diethylether. The remaining solution was flushed with $N_{2}$ and stored at $-18^{\circ}$. A double-wall all-glass reactor, thermostated at $60^{\circ}$ and equipped with a mechanical stirrer, was filled with $350 \mathrm{ml}$ of distilled deoxygenated water and 


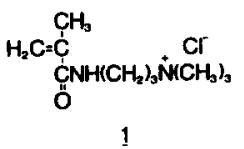

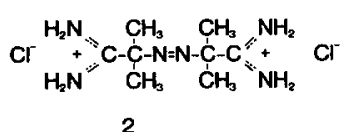

2

Scheme 1. Structure of MAD (1) and AIBA (2).

flushed with argon for $20 \mathrm{~min}$. Styrene $(30 \mathrm{~g})$ was then added to the reactor and after $5 \mathrm{~min}$ the desired amounts of MAD and AIBA were added together with $50 \mathrm{ml}$ of water. The emulsion polymerization was carried out under argon and the stirring speed was maintained at $300 \mathrm{rpm}$. Each polymerization was stopped after $\mathrm{ca} 16 \mathrm{hr}$ and the product was filtered through glass wool to remove any possible coagulum. All concentrations are based on the water volume.

Shot-growth experiments. The first step was identical to \$2 (see Table 2), i.e. $400 \mathrm{ml}$ water, $30 \mathrm{~g}$ styrene, $0.5 \mathrm{~g} \mathrm{MAD}$ and $0.5 \mathrm{~g}$ AIBA. A second batch of monomers was added after $3 \mathrm{hr}(6 \mathrm{~g}$ styrene, $150 \mathrm{mg}$ AIBA, a varying amount MAD and $50 \mathrm{ml}$ of water).

For kinetic experiments, samples were taken in order to monitor conversion and the polymerization was stopped by the addition of hydroquinone-monomethylether. After evaporation of the volatile components by heating at $90^{\circ}$ and drying of the sample under reduced pressure, the styrene conversion was determined by weight.

\section{Cleaning procedure}

The latex $(\approx 100 \mathrm{ml})$ was centrifuged twice $(20,000$ 30,000 rpm for 30 min, Centrikon T-2060), decanted, redispersed in water and then treated with 2-5 g silica (Merck, Kieselgel 60 for column chromatography, 63-200 $\mu \mathrm{m})$. After each treatment, the silica was filtered off on a paper filter. Silica treatment, followed by filtration was repeated twice. The latex was subsequently centrifuged twice before rinsing with aq. $\mathrm{NaOH}(\mathrm{pH}=11)$ in a serum-replacement cell provided with a $50 \mathrm{~nm}$ polycarbonate membrane (Nucleopore). After the passage of at least 15 cell volumes of diluted base, the cell was flushed with at least 20 cell volumes of deionized water followed by titration of the latex.

VIS spectra were recorded on a Hewlett-Packard diode array $8451 \mathrm{~A}$ spectrophotometer using a $1 \mathrm{~cm}$ cell. Average particle size and polydispersity were determined by Scanning Electron Microscopy (SEM).

\section{Titration}

An amount of latex was weighed and, where necessary, water was added to make up to a volume of $25 \mathrm{ml}$. The latex solution was flushed with argon for at least $30 \mathrm{~min}$. The inert atmosphere was maintained during the titration. The latex was titrated with $0.001 \mathrm{~N} \mathrm{HCl}$ solution. The conductivity was monitored using a Radiometer CDM80 conductivity meter. The surface charge density was calculated from latex solid contents and titration data.

\section{RESULTS AND DISCUSSION}

\section{Kinetics of emulsion polymerization}

Surfactant-free emulsion copolymerization with ionic comonomers is not as straightforward as it may seem, particularly because of the great difference between water-solubility of the two monomers. In a classical emulsion polymerization, i.e. the polymerization of a scarcely water-soluble monomer (e.g. styrene) in the presence of a water-soluble initiator and a surfactant, the kinetics may be described by the Smith-Ewart theory [32]. The most important mechanistic difference between a classical and a surfactant-free emulsion polymerization is the nucle- ation stage, the so-called stage I. In the case of conventional emulsion polymerization, particles may originate from monomer-swollen micelles activated by initiator radicals (micellar nucleation). Particle production stops when all surfactant molecules have been adsorbed on the already existing particles. This is the end of stage I. In the case of a surfactant-free emulsion polymerization, e.g. copolymerization of the scarcely water-soluble styrene with the water-soluble MAD, the homogeneous nucleation mechanism is likely to occur $[26,34]$. Thermal decomposition of the water-soluble initiator starts copolymerization of MAD with styrene in the water phase. Copolymerization in the water phase proceeds until the oligomer:

(i) is captured by already existing particles;

(ii) reaches a critical chain length after which it will "precipitate" to form a primary particle; or

(iii) terminates before it can be adsorbed or can nucleate [35].

These processes are dependent on the solubility (hydrophobic-hydrophilic balance) of the formed oligomer, the capturing ability of the already existing particles and the rate of termination of the oligomers in the water phase. Primary particles coalesce to larger particles until their surface charge provides sufficient colloidal stability. Particle production stops when all oligomeric radicals are captured by already existing stable particles before nucleation can occur.

The effect of MAD concentration on the styrene conversion as a function of time is shown in Fig. 1. An increase of the initial MAD concentration accelerates the rate of styrene conversion. Since the rate of polymerization is affected by the number of particles, the particle size of the resulting latices was measured as a function of the MAD concentration (Fig. 2). Indeed, the particle size drops on increasing the MAD concentration: it will be shown below that this is due to the increase of surface charge density.

To eliminate any possible influence of (very small concentrations of) polyelectrolyte in the commercially available MAD, unquaternized amine was treated with iodomethane. The ammonium salt thus formed appeared to be free of polyelectrolyte, and increased particle size in emulsion copolymerization

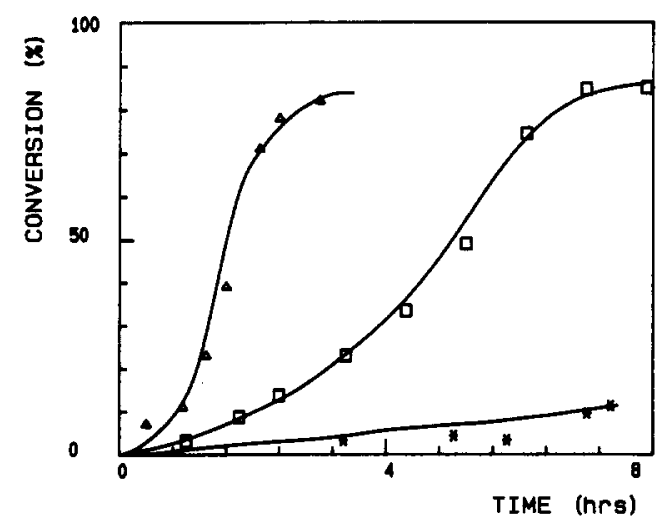

Fig. 1. Effect of MAD concentration on the styrene conversion. *, $[M A D]=0 \mathrm{~mol} / \mathrm{dm}^{3} ; \square,[M A D]=2.8 \times$ $10^{-3} \mathrm{~mol} / \mathrm{dm}^{3} ; \triangle,[\mathrm{MAD}]=5.7 \times 10^{-3} \mathrm{~mol} / \mathrm{dm}^{3}$ (for other experimental conditions see Fig. 2). 


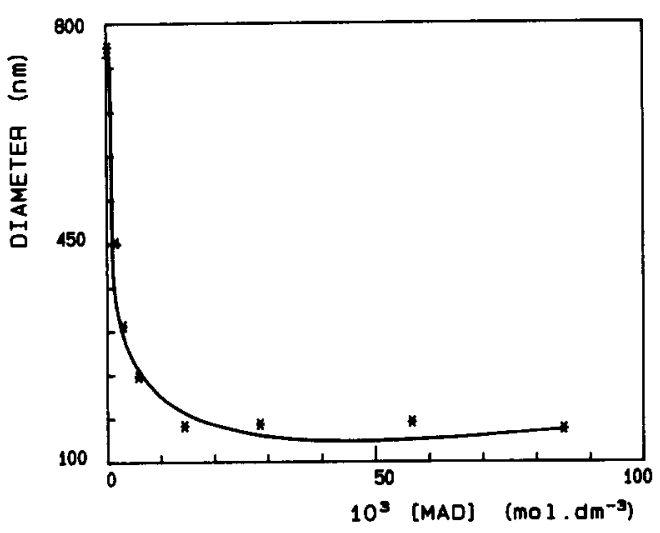

Fig. 2. Effect of MAD concentration on the particle size $\left[\right.$ styrene] $=0.72 \mathrm{~mol} / \mathrm{dm}^{3},\left[\right.$ AIBA] $=4.6 \times 10^{-3} \mathrm{~mol} / \mathrm{dm}^{3}$ $T=60^{\circ}$.

with styrene, compared with MAD under identical experimental conditions. In order to determine whether the origin of this unexpected phenomenon was due to the absence of polyelectrolyte or to the introduction of iodide, two emulsion polymerizations were carried out in the presence of MAD, one in the presence of $\mathrm{NaCl}$ and the other in that of equimolar $\mathrm{NaI}$. The conversion versus time curves (Fig. 3) clearly show that the retardation of styrene conversion is not caused by the presence of low concentrations of polyelectrolyte, but stems from the presence of the iodide salt. We are not aware of any publication reporting this effect. It appears that iodide reacts as a radical scavenger, thereby reducing the overall efficiency of the initiator and resulting in an increase of particle size. This effect is still under investigation.

\section{Latex purification}

Earlier work in our laboratory showed that the CoTSPc-catalysed thiol oxidation in the presence of cationic polymer is dependent on the linear charge density on the backbone of the polyelectrolyte. In this line of thought, the catalytic activity of the latices will also be affected by its surface charge density. It is therefore necessary to determine the surface charge density of the produced latices.

Because of the very great difference between the partition coefficients of the monomers, the formation of free water-soluble polyelectrolyte (i.e. copolymer of styrene and MAD not anchored onto the latex particles) is likely to occur. In order to determine the surface charge density reliably, these polymeric side products, together with low molar mass contaminants, must be removed prior to surface charge determination.

In addition, the CoTSPc catalytic system is extremely susceptible to very low concentrations of cationic polymer. We have found that, for the present homopolymer (PMAD), the thiol oxidation is affected at free polyelectrolyte levels corresponding to $\left[\mathrm{N}^{+}\right]=10^{-6} \mathrm{~mol} / \mathrm{dm}^{3}[36]$. In order to measure the true activity of the immobilized PMAD/latex system only, it is thus essential to clean the latex to such an extent as to obtain a polyelectrolyte concentration of the serum of the latex lower than
$\left[\mathrm{N}^{+}\right]=10^{-6} \mathrm{~mol} / \mathrm{dm}^{3}$. Aiming at the detection of extremely low concentrations of cationic polymer, we developed a VIS spectrophotometric method based on the occurrence of the dimeric or monomeric structure of CoTSPc in the presence or absence of these charged polymers, respectively $[37,38]$. Because of the very high extinction coefficient of CoTSPs and to the clear difference between the VIS spectra of these two structures, this technique provided an excellent and sufficiently sensitive method for determining trace amounts of polycations.

As a result of the smaller particle diameter, purification of the latex requires more sophisticated cleaning techniques than those available for resin particle cleaning. El-Aasser reviewed various latex-cleaning techniques [39], e.g. dialysis, ion-exchange [4], serum replacement [40, 41], microfiltration [42] and diafiltration [43]. Low molar mass impurities can generally be removed by one of these methods. On the other hand, the removal of polyelectrolyte by one of these methods will usually be more difficult [44].

The often used ion-exchange method alone is known to be insufficient to clean latices from polyelectrolyte [41, 45]. Moreover, the purification of the commercially available ion-exchange resin itself, i.e. the removal of charged polymeric contaminants, is laborious. We therefore purified polystyrene latices, stabilized by a block copolymer of styrene and quaternized 4-vinylpyridine, by using the ion-exchange method followed by serum replacement [38]. In that case, the combination of these two techniques appeared to be sufficient to cleanse the latex of polymeric contaminants. Unfortunately, this cleaning method was not satisfactory in all cases. Before developing a cleaning technique by ourselves, we tested three well-known purification methods for cleaning MAD stabilized polystyrene latices, viz. serum replacement, diafiltration and ultracentrifugation.

In the case of the serum replacement, Ahmed et al. [40] showed that the removal of salt from a diluted latex-containing low molar mass electrolyte is somewhat slower than expected theoretically implying interaction of the electrolyte with the polymer particle. It can be expected that in the present case, where interaction of polymeric contaminants with the latex

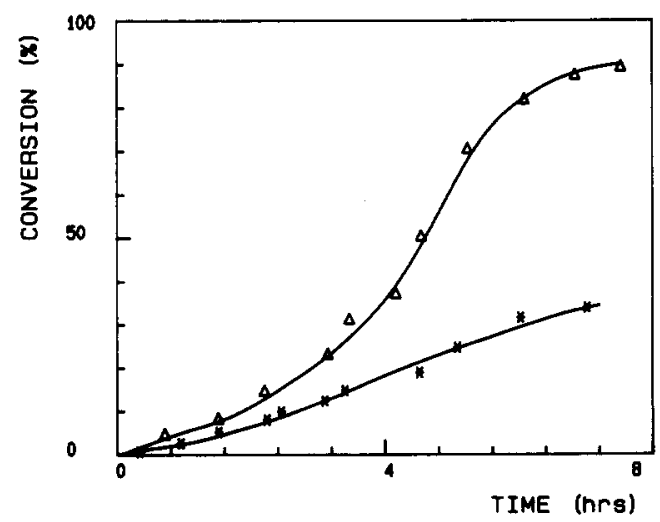

Fig. 3. Effect of the presence of iodide on the polymerization rate of styrene. $[\mathrm{MAD}]=1.15 \times 10^{-2} \mathrm{~mol} / \mathrm{dm}^{3}$; $[\mathrm{NaCl}]=[\mathrm{NaJ}]=1.0 \times 10^{-2} \mathrm{~mol} / \mathrm{dm}^{3} ; \Delta, \mathrm{NaCl} ; * \mathrm{NaJ}$ (for other experimental conditions see Fig. 2). 
is very likely, the cleaning process will be even more time consuming. Indeed we observed that the cleaning procedure could take days or weeks, depending on the water flow through the cell and on the conditions used during the emulsion polymerization, i.e. the concentration of the charged monomer. The total volume of cleaning water ranged between 30 and 100 times the cell volume before the polyelectrolyte concentration in the effluent of the serum replacement cell was less than $5 \times 10^{-7} \mathrm{~mol} / \mathrm{dm}^{3}$ as determined by the CoTSPc-VIS method.

Diafiltration, a technique very similar to serum replacement was also investigated. Instead of pumping water through the cell containing a latex solution, the latex is continuously circulated in a tangential flow pattern through channels over a membrane by the use of a pump, and, shear-induced coagulation may occur. In our case, this method did not appear to be faster than the serum-replacement technique as was claimed by others [42] and indeed, in some cases coagulation was observed.

Latices cleaned by serum replacement and diafiltration were tested by stirring a dilute latex solution for $15 \mathrm{~min}$ at $2600 \mathrm{rpm}$ at $25^{\circ}$, simulating the experimental conditions of the thiol oxidation. The resulting solution was centrifuged and the serum tested for the presence of polyelectrolyte by the CoTSPc-VIS method. In latices cleaned by serum replacement or diafiltration, unacceptably high levels of polyelectrolyte appeared to be desorbed after stirring. Apparently, both techniques purified the latex to such an extent as to leave some polyelectrolyte adsorbed to the latex surface. This polyelectrolyte desorbs so slowly that its concentration in the effluent is too low to be detected by the CoTSPc-VIS method $\left(\left[\mathrm{N}^{+}\right]<5 \times 10^{-7} \mathrm{~mol} / \mathrm{dm}^{3}\right)$. If, however, these cleaned latices were left to stand for approximately one week, or were subjected to vigorous stirring, the sera of the latices were found, after centrifugation, to contain detectable concentrations of polyelectrolyte.

Some authors claim the "complete" removal of polymeric contaminants by centifugation $[15,24,31]$. We also tried to clean latices this way, i.e. repeated centrifugation, followed by decantation and redispersion in water. Unfortunately, even after six centrifugations, the serum of the resulting latex still

Table 1. Effect of ionic strength on the desorption of polyelectrolyte as measured by the occurrence of monomeric or dimeric structure of CoTSPc in the sera of the precipitated latices

\begin{tabular}{lcc}
\hline $\begin{array}{c}\text { Number of } \\
\text { centrifugations }\end{array}$ & $\begin{array}{c}\text { Serum of } \\
\text { sample A }\end{array}$ & $\begin{array}{c}\text { Serum of } \\
\text { sample B }\end{array}$ \\
\hline 1 & - & - \\
2 & + & + \\
4 & + & + \\
\hline$-=$ absence of polyelectrolyte & according to \\
CoTSPc-VIS method. & \\
= presence of polyelectrolyte according to \\
CoTSPc-VIS method. \\
Sample A: (1) centrifugation, (2) redispersion in \\
distilled water followed by centrifugation, (3) \\
redispersion in $0.1 \mathrm{M}$ KNO ${ }_{3}$ followed by cen- \\
trifugation and (4) redispersion in distilled water \\
followed by centrifugation. Sample B: as sample \\
A, except for step (3) where distilled water was \\
used instead of $0.1 \mathrm{M}$ KNO ${ }_{3}$.
\end{tabular}

contained, at least for our catalytic systems, unacceptably high levels of polyelectrolyte. The technique is also very laborious. This cleaning method clearly demonstrated the effect of ionic strength of the serum on the desorption rate of polyelectrolyte (Table 1). As can be seen from Table 1, the CoTSPc-VIS method suggested, after one centrifugation of the latex, the absence of free polyelectrolyte (both samples $A$ and B). Much to our surprise, after redispersion of the remaining solid in pure water followed by a second centrifugation, the CoTSPc-VIS method indicated the presence of polyelectrolyte (both samples A and B). After redispersion of the solid in a salt solution $\left(0.1 \mathrm{M} \mathrm{KNO}_{3}\right)$ and subsequent centrifugation, the CoTSPc-VIS method again suggested the absence of polyelectrolyte (sample A), while the serum, after redispersion of the same solid in pure water, followed by centrifugation, contained polyelectrolyte according to our detection method (sample B). These findings are in good agreement with the theoretical considerations put forward by Hesselink [46]. The effect that the adsorption isotherm of charged polymers onto charged surfaces is determined by a coulombic and a nonionic adsorption term. If the charges have the same sign, as in our case, the latter must predominate, otherwise no adsorption would occur (the coulombic term has a negative effect on the adsorption isotherm due to the identical sign of the charges). Addition of salt will decrease the desorption rate as a result of a decrease in the electrostatic repulsion between the polyelectrolyte and the charged latex surface.

From all these attempts to clean the cationic latices, it became clear that, after using one of the known purification methods, the cleaned latices will contain unacceptably high levels of polyelectrolyte. For this reason, it was necessary to develop a method to clean latices to such an extent as to render polymer colloids suitable for the support of CoTSPc in catalytic systems.

It was found in our laboratory that cationic polymers like 2,4-ionene adsorb strongly to silica. Following this line of thought, we also tried to purify the cationic latices by this adsorption medium. In order to reduce simultaneously the amount of soluble charged polymer and the ionic strength of the latex solution, the latex was centrifuged twice before treatment with silica. Figure 4 shows the effect of silica treatment on the presence of polyelectrolyte in the sera of these latices, as determined by the CoTSPcVIS method. A treatment with silica consists of shaking the latex with silica for at least $12 \mathrm{hr}$, followed by filtration. Curve A shows the presence of polyelectrolyte in the serum after two centrifugations (presence of dimeric structure of CoTSPc at $630 \mathrm{~nm}$ ). Curve B clearly shows that after one treatment with silica the serum still contained polyelectrolyte. Curves $C$ and $D$ show that after 2 and 3 treatments of latex with silica the serum contained polyelectrolyte at concentrations below $5 \times 10^{-7} \mathrm{~mol} \mathrm{~N} / \mathrm{dm}^{3}$ (monomeric structure of CoTSPc at $660 \mathrm{~nm}$ ). To rid the latex of any possible further impurities undetectable by the CoTSPc-VIS method, the latex was centrifuged twice after being treated with silica. Most important of all, the sera of the latices remained free of polyelectrolyte after stirring at $2600 \mathrm{rpm}$ for 


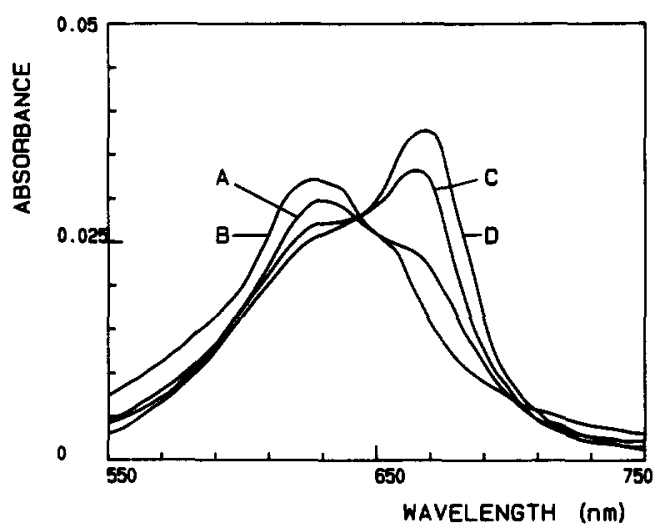

Fig. 4. The effect of cleaning latex with silica in the presence of polyelectrolyte in the serum. (A) After two centrifugations, (B) one treatment with silica followed centrifugation (C) two treatments with silica followed by centrifugation and (D) three treatments with silica.

$15 \mathrm{~min}$, nor could any polyelectrolyte be detected in the sera after the latex was left to stand for more than one week. The major difference between this cleaning technique and the common techniques is that, in the former case, the desorption of polyelectrolyte from the latex surface is enhanced by the addition of another strongly absorbing material during the collision of latex particles with the silica spheres whereas, in the traditional cleaning techniques, the desorption is purely controlled by the adsorptiondesorption equilibrium. The disadvantage of adding strongly adsorbing material is that in a few cases coagulation of the latex was observed during the cleaning process, probably initiated by the adsorption of cationic particles on the silica surface.

\section{Latex characterization}

Only a few techniques and few data appear to be available to characterize surface charge densities of cationic latices $[26,47]$. We tried to determine the surface charge by potentiometric titration of the latex with silver nitrate immediately after the silica cleaning procedure. All ammonium groups on the surface of the latex particles should have chloride as counterion. It was found that the surface charge density of various latices thus determined showed no relation to the initial MAD concentration. We therefore tried another, although more time-consuming technique, viz. replacement of the counterion with hydroxide by the serum replacement technique, rinsing the latex with dilute sodium hydroxide solution $(\mathrm{pH} \approx 11)$. This was followed by extensively washing of the latex with pure water to remove excess of base and by subsequent conductometric acid-base titration of the resulting latex. The surface charge densities so determined showed a satisfactory relation to the MAD content and were quite different from those determined by the silver nitrate method. These experiments suggest that cleaning of latices with silica replaces the chloride ion by an unknown counterion that does not precipitate on the addition of silver nitrate.

Figure 5 shows a typical titration curve of a latex, containing hydroxide as counterion. At first the

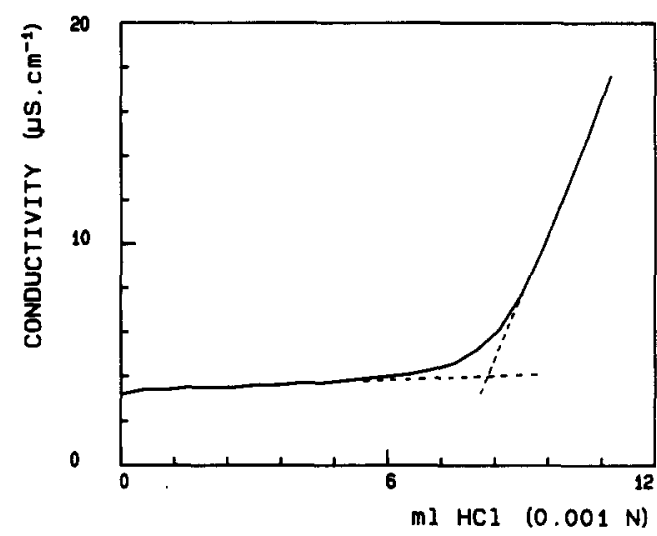

Fig. 5. Conductivity as a function of the amount of acid added to latex $\mathrm{S} 2[\mathrm{HCl}]=0.001 \mathrm{~mol} / \mathrm{dm}^{3}, 0.321 \mathrm{~g}$ (solid) in $25 \mathrm{ml}$ water.

conductivity of the latex solution hardly changes on the addition of the hydrochloric acid $\left(0.001 \mathrm{~mol} / \mathrm{dm}^{3}\right)$ indicatory of the reduced mobility of the counterion. When all the hydroxide ions have been replaced, the conductivity rises steeply as a result of the excess of acid. The number of basic groups on the particle surface can be calculated from the intersection of these two lines. The results of the titration are shown in Fig. 6 and Table 2. It can be seen that the surface charge density increases slightly on raising the initial MAD concentration confirming the conversion-time curves. Considering the high affinity-type adsorption isotherm of polymers [46], it seems reasonable to assume that, during the emulsion polymerization, polyelectrolyte is adsorbed by the growing particles and, in consequence, increases the colloidal stability of the growing particles. On further increasing the comonomer (MAD) concentration, more MADrich copolymer or even homopolymer formation is likely. The presence of more polyelectrolyte may result in:

(i) bridging between particles resulting in a broadening of the particle size distribution $\left(D_{w} / D_{n}\right)$;

(ii) continuous formation of primary particles resulting in a heterodisperse latex system.

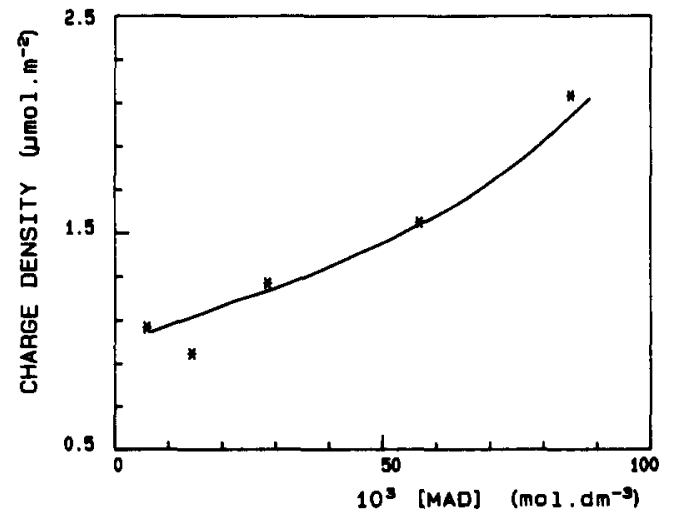

Fig. 6. Surface charge density $\left(\mu \mathrm{mol} / \mathrm{m}^{2}\right)$ as a function of the initial MAD concentration. 
Table 2. Particle size distribution and surface charge density of the latex particles at different MAD concentrations

\begin{tabular}{|c|c|c|c|c|c|}
\hline & \multirow{2}{*}{$\begin{array}{c}10^{3} \\
{[\mathrm{MAD}]} \\
\left(\mathrm{mol} / \mathrm{dm}^{3}\right)\end{array}$} & \multirow{2}{*}{$\begin{array}{c}D_{\mathrm{n}} \\
(\mathrm{nm})\end{array}$} & \multirow[b]{2}{*}{$D_{\mathrm{w}} / D_{\mathrm{n}}$} & \multicolumn{2}{|c|}{ Surface charge density } \\
\hline & & & & $(\mu \mathrm{mol} / \mathrm{g})$ & $\left(\mu \mathrm{mol} / \mathrm{m}^{2}\right)$ \\
\hline So & - & 760 & $\mathrm{~h}^{d}$ & $8.67^{\mathrm{a}}$ & - \\
\hline S1 & 2.8 & 317 & 1.02 & $-{ }^{b}$ & $-b$ \\
\hline s2 & 5.7 & 236 & 1.01 & 25.8 & 1.06 \\
\hline S3 & 14.2 & 156 & 1.02 & 34.5 & 0.94 \\
\hline S4 & 28.3 & 159 & 1.01 & 45.4 & 1.26 \\
\hline S5 & 56.6 & 162 & 1.06 & 54.5 & 1.54 \\
\hline S6 & 84.9 & 151 & 1.09 & 80.6 & 2.13 \\
\hline SDVB $^{c}{ }^{c}$ & 5.7 & 239 & $h^{d}$ & 18.9 & - \\
\hline SDVB2 ${ }^{\mathbf{c}}$ & 5.7 & 238 & $h^{d}$ & 19.3 & - \\
\hline
\end{tabular}

'Latex cleaned by serum replacement, followed by $\mathrm{AgNO}_{3}$ titration. 'Not determined.

'SDVB1 $=1 \%$ techn. DVB, SDVB2 $=3 \%$ techn. DVB

${ }^{d}$ Heterodisperse.

$\left[\right.$ AIBA] $=4.6 \times 10^{-3} \mathrm{~mol} / \mathrm{dm}^{3}$, [styrene] $=0.72 \mathrm{~mol} / \mathrm{dm}^{3}$ and $T=60^{\circ}$ (see Experimental Procedures).

The formation of nonanchored polyelectrolyte may be decreased by reducing the critical chain length of the growing water-soluble oligomeric radical. A possible way to reduce the critical chain length without affecting the charge density is the addition of the cross-linking agent (DVB). Moreover, the cationic charges anchored this way are chemically truly bonded to the latex particles. The results in Table 2 clearly show that the surface charge density decreases on the addition of DVB (compare S2 with SDVB1 and SDVB2). Moreover, the addition of cross-linker caused a broadening of the particle size distribution. Apparently, cross-linker addition causes a dual particle-formation mechanism.

Although many articles have been published on surfactant-free emulsion polymerization in the presence of an ionic comonomer, only few studies report surface charge densities. A review is given in Table 3. We emphasize that the different cleaning techniques used in these studies, together with the different extents of cleaning, will certainly affect the reported surface charge densities. In the case of emulsion polymerization of styrene with butyl acrylate and methylacrylic acid [15], the authors in fact suggest the incomplete removal of adsorbed polyelectrolyte.

The surface charge densities as given in Table 2 constitute cationic monomeric units and initiator residues at the ends of polymeric chains that have not been buried. Since immobilization of the slightly acidic protonated initiator residues $\left(\mathrm{pK}_{\mathrm{a}} \approx 12.5\right.$ $[48,49])$ on the latex surface will certainly decrease its $\mathrm{pK}_{\mathrm{a}}$ [25], a difference in basicity between two types of cationic groups both having a hydroxide as the counterion was to be expected. [50]. The titration curve (Fig. 5), however, clearly demonstrates that this distinction cannot be made. Although the concentration of initiator residues at the latex surface cannot be determined, an estimate can be made. Even at low MAD concentrations ([MAD] $=5.66 \times$ $\left.10^{-3} \mathrm{~mol} / \mathrm{dm}^{3}\right)$, the polymerization is completed within $3 \mathrm{hr}$ (see Fig. 1) meaning that $c a 30 \%$ of the initiator has thermally decomposed $\left(k_{\mathrm{d}}(\mathrm{AIBA})=\right.$ $3.22 \times 10^{-5} \mathrm{sec}^{-1}$, at $60^{\circ}$ [51]). From the polymerization conditions, as given in Experimental Procedures, the maximum charge density per unit of weight due exclusively to initiator residues can now be calculated. They amount to $37 \mu \mathrm{mol} / \mathrm{g}$. It must be noted that this can only be the case if all decomposed initiator radicals induce polymerization, no free polyelectrolyte is formed and no initiator residues are being buried in the latex particles. Clearly, these prerequisites do not hold in the present case; the efficiency of the initiator will be less than unity (for solution polymerization this value usually ranges between 0.6-1 [52]), polyelectrolyte is formed and initiator residues will be buried inside latex particles. Assuming an efficiency of 0.7 , the maximum concentration of initiator molecules at the latex surface is $26 \mu \mathrm{mol} / \mathrm{g}$. The surface charge density of S0 is much lower than this theoretical value $([\mathrm{MAD}]=0$, Table 2. It should be noted that the reaction time in this case was much longer than $3 \mathrm{hr}$ ). Liu et al. reported a surface charge density to AIBA residues of $10.3 \mu \mathrm{mol} / \mathrm{g}$ in the case of EMVPB (total charge density is $15.3 \mu \mathrm{mol} / \mathrm{g}$, see Table 3 ).

Although the addition of charged comonomer results in latices having a higher solid content and a greater surface charge density than in the absence of ionic monomer, the surface charge may be further increased by the so-called seeded-growth method and shot-growth emulsion polymerization. The difference between these two methods is that in the latter case, a second charge of monomer is added to the emulsion while the first charge is still reacting. In a seededgrowth experiment the latex (seed) is purified before a second emulsion polymerization is carried out. It is claimed that a better morphology as well as an increase of surface charge density $[45,54]$ can be achieved in the case of the shot-growth method compared with the seeded-growth technique [53]. This phenomenon has been explained by a difference in swelling behaviour between a purified (i.e. monomer free) and nonpurified latex $[53,55,56]$ or by the presence of oligomeric radicals in the slightly monomer-swollen particles $[57,58]$. The results of the shot-growth method are given in Table 4. The experimental conditions used during the first charge of the shot-growth reaction were identical to those used to synthesize latex S2 (see Table 2 and Experimental Procedures). After $3 \mathrm{hr}$ (conversion $>80 \%$ ), a second charge of monomer, comonomer, initiator and water is added. It can be concluded that the surface charge

Table 3. Surface charge densities of several latices produced by surfactant-free emulsion polymerization in the presence of an ionic comonomer

\begin{tabular}{|c|c|c|c|}
\hline \multirow[b]{2}{*}{ System } & \multirow{2}{*}{$\underset{(\mathrm{nm})}{D}$} & \multicolumn{2}{|c|}{ Surface charge density } \\
\hline & & $(\mu \mathrm{mol} / \mathrm{g})$ & $\left(\mu \mathrm{mol} / \mathrm{m}^{2}\right)$ \\
\hline$\overline{\text { STY/NaSS }}{ }^{10}$ & 236 & 21.2 & 0.87 \\
\hline STY/BuAc/MAA ${ }^{15}$ & 272 & 15.7 & 0.75 \\
\hline STY/BuAc/MAA ${ }^{15}$ & 208 & 104.9 & 3.82 \\
\hline STY/NaSS ${ }^{40}$ & 165 & 35.2 & 1.02 \\
\hline STY/NaVTS 40 & 84 & 36.1 & 0.53 \\
\hline BuAc/AA ${ }^{59}$ & 67 & 93.0 & 1.09 \\
\hline STY/EMVPB ${ }^{26}$ & 390 & 15.3 & 1.05 \\
\hline STY/DVPM ${ }^{26}$ & 280 & 19.7 & 0.97 \\
\hline STY/AMPS ${ }^{13}$ & 280 & 40.7 & 1.99 \\
\hline STY/TMA ${ }^{60}$ & 120 & 56.4 & 1.18 \\
\hline STY/MAD (S6) & 151 & 80.6 & 2.13 \\
\hline
\end{tabular}

STY, styrene; BuAc, butyl acrylate; MAA, methylacrylic acid; NaSS, sodium styrene sulphonate; NaVTS, sodium vinyltoluene sulphonate; AA, acrylic acid; EMVPB, 1-ethyl 2-methyl 5-vinylpyridinium bromide; DVPM, 1,2-dimethyl 5-vinylpyridinium methylsulphate; AMPS, 2-acrylamido-2-methyl propane sulphonic acid; TMA, $N$-trimethyl $N$-ethyl methacrylate ammonium iodide. 
Table 4. Surface charge density of latices produced by the shotgrowth method

\begin{tabular}{lccccc}
\hline & & & & \multicolumn{2}{c}{ Surface charge density } \\
\cline { 5 - 6 } Latex & $\begin{array}{c}10^{3}[\mathrm{MAD}] \\
\left(\mathrm{mol} / \mathrm{dm}^{3}\right)\end{array}$ & $\begin{array}{c}D \\
(\mathrm{~nm})\end{array}$ & $D_{\mathrm{w}} / D_{\mathrm{n}}$ & $(\mu \mathrm{mol} / \mathrm{g})$ & $\left(\mu \mathrm{mol} / \mathrm{m}^{2}\right)$ \\
\hline SG1 & 12.6 & 220 & 1.01 & 26.0 & 1.00 \\
SG2 & 25.2 & 204 & 1.02 & 28.8 & 1.03 \\
SG3 & 50.3 & 214 & 1.01 & 32.6 & 1.22 \\
SG4 & 75.5 & 218 & 1.16 & 30.9 & 1.18 \\
\hline
\end{tabular}

"Experimental details are given in Experimental Procedures.

density increases slightly by using the shot-growth technique. For high concentration of MAD, the resulting latex had a higher polydispersity. The production of latices with a relatively high polydispersity by the addition of a second charge at low conversion $50 \%$ ) agrees closely with the findings of Sakato [45].

From the batch and shot-growth experiments (Tables 2 and 4), it can be concluded that in both cases the addition of comonomer slightly increases the surface charge density. Increasing the comonomer concentration will increase the total surface (as a result of particle-size reduction) and therefore more comonomer can be built in (increase of total charge per unit of weight, $\mu \mathrm{mol} / \mathrm{g}$ ). We postulate that MAD can be built into the latex surface only up to a certain level of charge density. As soon as this level is reached, the incoming comonomer-rich oligomeric radicals are prevented from entering and inducing polymerization in the particles as a result of coulombic repulsion. The shot-growth experiments confirm this view. The quasi indifference of surface charge densities presented in Table 3 to changing the comonomer, despite the great difference between ionic comonomers and the various experimental conditions used to prepare these functionalized latices, can also be understood on these grounds.

A possible alternative route for synthesizing highly charged latices and simultaneously avoiding the formation of free polyelectrolyte is the post polymerization method [3]. However, some drawbacks are introduced by this technique:

(i) large (unstable) particles are produced in the case of surfactant-free emulsion copolymerization of a hydrophobic monomer;

(ii) large quantities of comonomer are buried inside the polymer particles and thus are unavailable for functionalization; and

(iii) functionalization may be incomplete as a result of the formation of highly charged surface during the modification.

\section{CONCLUSION}

3-(Methacrylamidinopropyl)trimethylammoniumchloride (MAD) can be used as a comonomer in the emulsion polymerization of styrene with AIBA as initiator. Increasing comonomer concentration appeared to increase the conversion rate of styrene, an effect which can be attributed to particle size reduction. Since the latices will be used as a support for CoTSPc, a catalyst in the thiol oxidation, and since this catalytic system is extremely sensitive to low concentrations of free polyelectrolyte, the latices must be thoroughly cleaned prior to use in the catalytic reaction. Conventional purification techniques like serum replacement, diafiltration and centrifugation were found to be insufficient and continuous desorption could be observed on standing or after stirring. Centrifugation of latices, followed by treatment with silica, was found to clean the latices to such an extent as to lead to serum-containing polyelectrolyte concentrations lower than $\left[\mathrm{N}^{+}\right]<5 \times 10^{-7} \mathrm{~mol} / \mathrm{dm}^{3}$. Surface charge density as determined by conductometric acid-base titrations increased on increasing MAD concentration. Addition of a cross-linking agent (DVB) decreased the surface charge density and broadened the particle size distribution. So-called shot-growth emulsion polymerization hardly increased the surface charge density.

Acknowledgements-This investigation was supported by the Netherlands Foundation for Chemical Research (SON) with financial aid from the Netherlands Organization for Scientific Research (NWO) and the Netherlands Foundation for Emulsion Polymerization (SEP).

\section{REFERENCES}

1. P. Hodge and D. C. Sherrington (Eds). PolymerSupported Reactions in Organic Synthesis. Wiley, Chichester (1980).

2. D. C. Sherrington and P. Hodge (Eds). Synthesis and Separations using Functional Polymers. Wiley, Chichester (1988).

3. D. A. Upson. J. Polym. Sci. Polym. Symp. 72, 45 (1985).

4. J. W. Vanderhoff, H. J. van den Hul, R. J. M. Tausk and J. Th. G. Overbeek. In Clean Surfaces: Their Preparation and Characterization for Interfacial Studies (edited by G. Goldfinger). Marcel Dekker, New York (1970).

5. H. J. van den Hul and J. W. Vanderhoff. Br. Polym. J. 2, $121(1970)$.

6. J. W. Goodwin, J. Hearn, C. C. Ho and R. H. Ottewill. Colloid Polym. Sci. 252, 464 (1974).

7. H. J. van den Hul and J. W. Vanderhoff. J. Colloid Interface Sci. 28, 336 (1968).

8. A. M. Homola, M. Inoue and A. A. Robertson. J. appl. Polym. Sci. 19, 3077 (1975)

9. M. Okubo, A. Yamada, S. Shibao, K. Nakamae and T. Matsumoto. J. appl. Polym. Sci. 26, 1675 (1981).

10. M. S. Jang and I. M. Krieger. J. Polym. Sci.; Polym. Chem. Edn 14, 2089 (1976).

11. Y. Chonde and I. M. Krieger. J. appl. Polym. Sci. 26, 1819 (1981).

12. H. S. Chang and S. A. Chen. J. Polym. Sci.; Polym. Chem. Edn 26, 1207 (1988).

13. R. L. Schild and M. S. El-Aasser, G. W. Poehlein and J. W. Vanderhoff. In Emulsions, Latices and Dispersions (edited by P. Becher and M. N. Yudenfreund), p. 99. Marcel Dekker, New York (1978).

14. S. R. Turner, R. A. Weiss and R. D. Lundberg. J. Polym. Sci.; Polym. Chem. Edn 23, 535 (1985).

15. J. L. Guillaume, C. Pichot and J. Guillot. J. Polym. Sci.; Polym. Chem. Edn 26, 1937 (1988).

16. J. Barton and V. Juranicova. Chem. Papers 41, 113 (1987).

17. G. W. Ceska. J. appl. Polym. Sci. 18, 427 (1974).

18. G. G. Cameron. Makromolek. Chem. 2, 271 (1982).

19. U. S. Satpathy and A. S. Dunn. Br. Polym. J. 20, 521 (1988).

20. D. C. Blackley. In Science and Technology of Polymer Colloids (edited by G. W. Poehlein, R. H. Ottewill and J. W. Goodwin), p. 203, Nato ASI Series E67. Martinus Nijhoff Publishers, Boston (1983).

21. H. Kawaguchi, Y. Sugi and Y. Ohtsuka. J. appl. Polym. Sci. 26, 1649 (1981). 
22. F. Hoshino, T. Fujimoto, H. Kawaguchi and $Y$. Ohtsuka. Polym. J. 19, 241 (1987).

23. Y. Ohtsuka, H. Kawaguchi and Y. Sugi. J. appl. Polym. Sci. 26, 1637 (1981).

24. H. Tamai, T. Murakami and T. Suzawa. J. appl. Polym. Sci. 30, 3857 (1985).

25. J. W. Goodwin, R. H. Ottewill and R. Pelton. Colloid Polym. Sci. 257, 61 (1979).

26. L. J. Liu and I. M. Krieger. J. Polym. Sci.; Polym. Chem. Edn 19, 3013 (1981).

27. K. Sakota and T. Okaya. J. appl. Polym. Sci. 20, 1725 (1976).

28. Y. Ohtsuka, H. Kawaguchi and S. Watanabe. Polymer 21, 1073 (1980).

29. Y. Ohtsuka, H. Kawaguchi and S. Hayashi. Polymer 22 , 658 (1981).

30. B. W. Greene, D. P. Sheetz and T. D. Filer. J. Colloid Interface. Sci. 32, 90 (1970).

31. S-L. Tsaur and R. M. Fitch. J. Colloid Interface Sci. 115,450 (1987).

32. M. Hassanein and W. T. Ford. J. org. Chem. 54, 3106 (1989).

33. D. C. Blackley. Emulsion Polymerization. Applied Science, Barking, England (1975).

34. R. M. Fitch and C. H. Tsai. In Polymer Colloids (edited by R. M. Fitch), p. 73. Plenum Press, New York (1971).

35. F. K. Hansen and J. Ugelstad. In Emulsion Polymerization (edited by I. Piirma), p. 51. Academic Press, New York (1982).

36. K. H. Van Streun, P. Piet and A. L. German. Eur. Polym. J. 23, 941 (1987).

37. K. H. van Streun, J. Meuldijk and A. L. German. Angew. Makromolek. Chem. 173, 119 (1989).

38. K. H. van Streun, R. Tennebroek, P. Piet and A. L. German. Makromolek. Chem. 191, 2181 (1990).

39. M. S. El-Aasser. In Science and Technology of Polymer Colloids (edited by G. W. Poehlein, R. H. Ottewill and J. W. Goodwin), p. 422. Nato ASI Series E67, Martinus Nijhoff Publishers, Boston (1983).

40. S. M. Ahmed, M. S. El-Aasser, G. H. Pauli, G. W. Poehlein and J. W. Vanderhoff. J. Colloid Interface Sci. 73, 388 (1980)

41. W. E. Daniels, J. W. Vanderhoff, C. T. Enos, J. G. Iacoviello, S. M. Ahmed and J. Frost. In Emulsion
Polymerization of Vinylacetate (edited by M. S. ElAasser and J. W. Vanderhoff), p. 292. Applied Science, London (1981).

42. M. C. Wilkinson, J. Hearn, P. Cope and M. Chalney. Br. Polym. J. 13, 82 (1981).

43. M. E. Labib and A. A. Robertson. J. Colloid Interface Sci. 67, 543 (1978).

44. Y. Chonde and I. M. Krieger. J. Colloid Interface Sci. 77, 138 (1980).

45. K. Sakota and T. Okaya. J. appl. Polym. Sci. 20, 1735 (1976).

46. F. Th. Hesselink. In Adsorption from Solution at the Solid/Liquid Interface (edited by G. D. Parfitt and C. H. Rochester), Chap. 8. Academic Press, London (1983).

47. B. Verrier, Y. Chevalier, C. Pichot and A. Revillon. In Deuxieme colloque international sur les copolymerizations et les copolymers en milieu disperse, 3-7 avril 1989, Lyon, p. 167.

48. G. S. Hammond and R. C. Neuman. J. Am. Chem. Soc. 85, 1501 (1963)

49. K. Ito. J. Polym. Sci.; Polym. Chem. Edn 11, 1673 (1973).

50. R. Kunin. Ion-Exchange Resins. R. E. Krieger Publishing Company, Huntington, New York (1972).

51. N. Minamii, B. Yamada and T. Otsu. Mem. Fac. Eng. Osaka City Univ. 28, 101 (1987).

52. F. A. Bovey and F. H. Winslow (Eds). Macromolecules. Academic Press, New York (1979).

53. M. Chalney, M. C. Wilkinson and J. Hearn. Ind. Engng Chem. Prod. Res. Dev. 21, 171 (1982).

54. J-H. Kim. Ph.D. Thesis, Lehigh University, Bethlehem, U.S. (1987).

55. Y. Chung-li, J. W. Goodwin and R. H. Ottewill. Progr. Colloid Polym. Sci. 60, 163 (1976).

56. J. W. Goodwin, R. H. Ottewill, N. M. Harris and J. Tabony. J. Colloid Interface Sci. 78, 253 (1980).

57. D. Mangeraj and S. B. Rath. Polym. Prepr. Am. Chem. Soc. Polym. 13, 349 (1972).

58. C. Hagiopol, M. Georgescu and I. Deaconescu. Makromolek. Chem. Suppl. 10, 159 (1985).

59. B. Emelie, C. Pichot and J. Guillot. Makromolek. Chem. 189, 1879 (1988).

60. W. M. Brouwer, M. van der Vegt and P. van Haeren. Eur. Polym. J. 26, 35 (1990) 